\title{
SALIVARY CORTISOL FROM EMPLOYEES SUBJECTED OR NOT TO LABOR GYMNASTICS
}

\author{
Pedro H. Fidelis (IC); Patrícia T. Ricardo (PQ); Heloísa Aparecida Ferreira (PQ); Aglécio Luiz Souza (PQ); \\ Isabela V. Vieira (IC); Fernando Canova (PQ); Dora M. Grassi-Kassisse (PQ)
}

\section{Abstract}

We evaluate the stress index (questionnaire of perceived stress and salivary cortisol concentrations) in employees that participated or not in labor gymnastics (LG). The results show that LG didn't interfere with the rhythmicity or total amount of cortisol produced in the practicing population.

Keywords: employees, stress, Labor gymnastics.

\section{Introduction}

The work environment or the individual's occupation itself can be stress factors for some people. Labor stress triggers performance drop, absenteeism and susceptibility to the onset of diseases. Labor Gymnastics (LG) is practiced with the purpose of prevention of occupational diseases. This study aimed to evaluate the perceived stress index (PSI) and salivary cortisol concentrations in employees of the Biology Institute at UNICAMP, LG practitioners or not. We also evaluate the initial impact of LG practice on stress indicators in volunteers who participated in the survey. Part of the study was already published $^{1}$, where we demonstrated that volunteers who practiced LG presented a PSI lower than a non-practicing group (control). Ethics committee number in research: CAEE: 0560.0.146.000-08

\section{Results and Discussion}

Volunteers of the control group showed rhythmicity in daily production of cortisol on days of rest and activity, while the LG population showed rhythmicity only in samples collected on days of rest. There were no changes in the amount of cortisol produced in samples from days of rest and days of activity in the control population and the LG population. There were no significant differences in the total amount (AUC) of cortisol produced in days of rest and activity in the same population and amongst populations.

Chart 1. Salivary cortisol concentration of control volunteers and volunteers submitted to Labor Gymnastics on days of rest and activity.

\begin{tabular}{|c|c|c|c|}
\hline A & \multicolumn{3}{|c|}{ Control Group } \\
\hline $\begin{array}{c}\text { Cortisol, } \\
\mathrm{ng} / \mathrm{mL}\end{array}$ & Rest & Activity ( $1^{\circ}$ collection) & Activity $\left(2^{\circ}\right.$ collection $)$ \\
\hline 6:00h & $20,11 \pm 2,80(10)$ & $19,09 \pm 3,29(10)$ & $17,84 \pm 2,59(10)$ \\
\hline 12:00h & $11,85 \pm 2,16(10)^{*}$ & $9,47 \pm 1,26(10)^{*}$ & $10,71 \pm 2,07(10)^{\star}$ \\
\hline 19:00h & $9,40 \pm 2,53(10)^{*}$ & $7,55 \pm 1,33(10)^{*}$ & $7,96 \pm 1,62(10)^{*}$ \\
\hline $23: 00 \mathrm{~h}$ & $5,09 \pm 2,53(10)^{\star}$ & $6,31 \pm 1,27(10)^{*}$ & $5,61 \pm 1,16(10)^{\star}$ \\
\hline AUC & $199,26 \pm 30,55(10)$ & $173,04 \pm 16,97(10)$ & $178,17 \pm 27,42(10)$ \\
\hline & 0,0307 & 0,0032 & 0,1292 \\
\hline B & \multicolumn{3}{|c|}{ Labor Gymnastics Group } \\
\hline $\begin{array}{c}\text { Cortisol, } \\
\mathrm{ng} / \mathrm{mL}\end{array}$ & Rest & Activity ( $1{ }^{\circ}$ collection) & Activity ( $2^{\circ}$ collection) \\
\hline $6: 00 \mathrm{~h}$ & $22,51 \pm 7,20(4)$ & $11,80 \pm 4,91(4)$ & $19,75 \pm 3,06(4)$ \\
\hline $12: 00 \mathrm{~h}$ & $9,46 \pm 2,65(4)$ & $12,84 \pm 5,43(4)$ & $9,33 \pm 2,74(4)$ \\
\hline $19: 00 \mathrm{~h}$ & $5,71 \pm 0,72(4)^{\star}$ & $6,47 \pm 2,20(4)$ & $9,85 \pm 4,39(4)$ \\
\hline $23: 00 \mathrm{~h}$ & $6,17 \pm 1,45(4)^{*}$ & $7,57 \pm 1,96(4)$ & $4,29 \pm 0,22(4)^{*}$ \\
\hline AUC & $172,73 \pm 33,703(4)$ & $169,57 \pm 25,78(4)$ & $182,70 \pm 36,20(4)$ \\
\hline & 0,0337 & 0,6121 & 0,0228 \\
\hline
\end{tabular}

Cortisol concentration of samples from volunteers of the control group (A) and LG practitioners $(B)$. The samples were collected in three days, a day of rest and two of labor activity. In each of the days the collections happened upon waking up (6am); before lunch (12h) before dinner (19h) and before bed (23h). The daily production was assessed by calculating the area under the curve of each daily result. Data normality was identified by Kolmogorov-Smirnov, and the statistical differences were evaluated by ANOVA followed by Dunnet's test. The significance was considered when $p<0.05$. Both the $p$-value and the number of volunteers are indicated in the table.

\section{Conclusions}

Although the results from the questionnaire (PSI) had indicated that the LG practitioners showed lower scores of stress, the evaluated cortisol concentrations did not validated this statement. The results obtained by analysis of the salivary cortisol show that the practice of LG doesn't interfere in neither the rhythmicity or the total amount of cortisol produced by the practitioner population evaluated in this study.

\section{Acknowledgement}

Capes, CNPq e SAE
PT

http://www.bibliotecadigital.unicamp.br/document/?code $=000648$ $011 \& \mathrm{opt}=4$. 